\title{
Aprendizaje ubicuo, interfaces de comunicación y las competencias mediáticas
}

\section{Ubiquitous learning, communication interfaces and media skills}

\author{
Soraya María Ferreira Vieira \\ Universidad Federal de Juiz de Fora. Facultad de Comunicación Social (UFJF) \\ sovferreira@gmail.com \\ Código Orcid: https://orcid.org/0000-00021147-4987
}

Luana Castilho

Universidad Federal de Juiz de Fora. Facultad de Comunicación Social (UFJF)

luanacastilho@gmail.com

Código Orcid: https://orcid.org/0000-0001-6049-4688

\begin{abstract}
Resumen
El presente trabajo trata de la hipermovilidad que genera nuevas posibilidades de aprendizaje que proponen nuevos desafíos a los productores de contenido y a los educadores. El aprendizaje ubicuo deriva de estos nuevos ambientes hiperconectados y, aunque incorpore características del m-learning, no constituye un plan educacional, es totalmente informal, es "espontánea, contingente, caótica y fragmentaria". Este trabajo se propone destacar, en este contexto, una experiencia brasileña: la aplicación Geekie Games, que tiene el objetivo de ayudar a los candidatos en la preparación para el ENEM (Examen Nacional de la Enseñanza Media) y está disponible en las tiendas online de dispositivos móviles con el sistema operativo Android. El usuario puede acceder a los simuladores, vídeo-clases expositivas animadas y tutoriales, imágenes y ejercicios específicos de cada disciplina, desarrollados por la Fundación Lemann en asociación con otras instituciones del sector privado y con el apoyo del Ministerio de la Educación. Aquí haremos una primera reflexión respecto a cómo este nuevo dispositivo está relacionado con las competencias mediáticas y sus dimensiones, como las conceptuadas por Ferrés. Los flujos de comunicación se vuelven intensos en la era de la hipermovilidad y la ubicuidad. Los dispositivos móviles han sido grandes protagonistas en esta ecología comunicacional que se diseña y cambia el aprendizaje.
\end{abstract}

\section{Palabras clave}

Aprendizaje ubicuo, juego, dispositivos móviles, competencia mediática, tactibilidad, hipermobilidad.

Forma sugerida de citar: Ferreira, Soraya y Castilho, Luana (2018). Aprendizaje ubicuo, interfaces de comunicación y las competencias mediáticas. Universitas, 29, pp. 201-215. 


\begin{abstract}
The present work deals with the hypermobility that generates new possibilities of learning that propose new challenges to the producers of content and the educators. Ubiquitous learning derives from these new hyperconnected environments and, although it incorporates m-learning characteristics, it does not constitute an educational plan, it is totally informal, it is "spontaneous, contingent, chaotic and fragmented". In this context, a Brazilian experience: the Geekie Games application, which aims to assist candidates in preparing for the ENEM (National Examination of Secondary Education) and is available in the online stores of mobile devices with the Android operating system. The user can access the simulated, animated video-lectures and tutorials, images and exercises specific to each discipline, developed by the Lemann Foundation, in partnership with other institutions of the private sector and with the support of the Ministry of Education. A first reflection on how this new device is related to media skills and its dimensions, as conceptualized by Ferrés. Communication flows become intense in the era of hypermobility and ubiquity. Mobile devices have been a great protagonist in this communicational ecology that is designed and changing learning.
\end{abstract}

\title{
Keywords
}

Ubiquitous learning, game, mobiles device, media competence, tactility, hypermobility.

\section{Introducción}

El surgimiento y la popularidad de los dispositivos móviles digitales cambiaron la relación entre hombre, tecnología y ambiente. Con la convergencia mediática, los artefactos técnicos pasaron a desempeñar diferentes funciones, muchas incluso, que extrapolan el objetivo central de la comunicación interpersonal. Hoy, con un solo aparato, es posible organizar la agenda, monitorear latidos cardíacos, reservar el alojamiento en un hotel, verificar la ubicación del autobús en tiempo real, ver vídeos, administrar perfiles en las redes sociales, además de enviar y recibir e-mails, enviar mensajes y hablar por teléfono. Además de la facilitación de concentrar numerosas funciones en un único dispositivo, el avance tecnológico permitió que se sumara a ello la movilidad informacional. Con el advenimiento de los celulares, notebooks, paginadores, palmtops, etc. se dio inicio a ese movimiento, pero la estructura técnica restringía las potencialidades de estos aparatos, 
en la medida en que las conexiones todavía necesitaban soporte técnico y la movilidad informacional era reducida. A partir de la creación de las redes $3 \mathrm{G}$ y $4 \mathrm{G}$, la tecnología Wi-Fi y la conexión Bluetooth, los dispositivos georreferenciales garantizaron que las conexiones también pudieran ser móviles, propiciando la hipermobilidad (Santaella, 2013), que amplía y refina los modos de presencia que se expanden a medida que las tecnologías están más disponibles y móviles, propiciando mayores flujos de información y conectividad. Lo que se plantea con fuerza en este ambiente convergente es justamente el modo de distribución de la información.

El usuario, a su vez, tiene en su cotidiano cada vez más la presencia de esos dispositivos, que pasan a mediar parte significativa de sus interacciones, ya sea interpersonal, con el ambiente, con sus tareas diarias, con su ocio, con sus emociones. Cada vez los sentimientos también pasan a figurar y configurar la intimidad que también habita en el ambiente convergente. La revolución digital trae consigo una transformación en el comportamiento del, hasta entonces, receptor. La cultura participativa (Jenkins, 2009) es el gran fenómeno que viene alterando todos los procesos que envuelve la comunicación. La producción ahora pasa a ser pensada, o debería ser, en las posibilidades de interacción y retroalimentación.

$\mathrm{Si}$ antes el medio, el mensaje y quien la transmitía concentraban mayoritariamente los esfuerzos del pensamiento científico, hoy, aunque no se excluyan esos elementos anteriores, es el receptor $-\mathrm{o}$ el nuevo usuario, prosumidor - quien guía los estudios que buscan comprender las nuevas prácticas de comunicación. Jenkins (2009) señala esta tendencia al abordar la cultura participativa, colocando al proceso colectivo como elemento central de las prácticas de consumo informacional.

El público, por otra parte, desarrolla otros estímulos con el contenido que interactúa. Antes, el medio definía el sentido afectado en la recepción como vista, oído, olfato. Ahora, la relación ocurre en esferas multisensoriales, incluso táctiles, con las interfaces hápticas de los teléfonos inteligentes y tabletas (Haywards et al., 2004 en Palacios y Cunha, 2012, p. 2). Santaella argumenta que esos aparatos "se relacionan con usuarios de modos nuevos, engranan nuestros sentidos y nuestro cuerpo de maneras diferentes" (2010, p. 69). Defiende que todo y casi toda la gente son mediados por la tecnología digital, incluso las prácticas educacionales.

En el ambiente hiperconectado dado por el contexto de la convergencia mediática, como mencionamos arriba y las modalidades de aprendiza- 
je que de ahí derivan, traen la necesidad de repensar los estudios de "midaeducación". Los flujos de comunicación se vuelven intensos en la era de la hipermobilidad y la ubicuidad. Los dispositivos móviles han sido un gran protagonista en esta ecología comunicacional que se diseña, así como los usuarios que se insertan en esta nueva cartografía social, sin embargo, ¿estamos hábiles para hacer frente a estas nuevas formas de comunicación y dispositivos?, ¿cómo es nuestra implicación con las interfaces utilizadas en el ambiente hiperconectado que estimula la autonomía, la colaboración, la organización y operacionalización de múltiples tareas? Se busca entender este fenómeno a la luz de las competencias mediáticas.

\section{Nuevos modelos de aprendizaje y el aprendizaje ubicuo}

Desde la interacción con las nuevas tecnologías comunicacionales, surgen nuevos modelos de enseñanza-aprendizaje. Santaella (2011) destaca el surgimiento del e-learning, m-learning y el aprendizaje ubicuo. En esos paradigmas, el soporte posibilitó un desplazamiento de los procesos educacionales a los ambientes domésticos, de trabajo y las calles, todos ellos en movimiento. El consumo y la fruición de las informaciones se volvieron más individualizados y personalizados, al mismo tiempo, esas modalidades estimularon prácticas más colaborativas y participativas, que favorecieron modalidades de aprendizaje autodidactas.

El uso intensivo de las TIC con el objeto de realizar búsquedas online, acceder a diversos contenidos e incluso para construir el repertorio intelectual de los individuos y establecer las relaciones de sentido, ha reconfigurado la relación de los usuarios con los contenidos informacionales, generando formas espontáneas de educación.

En la perspectiva educacional, Belloni y Gomes defienden que las TIC proporcionan un ambiente eficaz para las prácticas educacionales. Los aprendientes se relacionan con colegas, con adultos más experimentados, comparten y debaten opiniones, construyendo un conocimiento colaborativo y participativo. Las autoras también argumentan que la autonomía es una competencia esencial para el proceso de aprendizaje y muy estimulada en la absorción de contenidos a través de las TIC. A la hora de decidir cuáles herramientas y funciones de los dispositivos usar, la ruta de navegación y cómo elaborar un texto, el usuario participa de un medio de aprendizaje 
más favorable, principalmente en los casos de niños y jóvenes que se dan cuenta que pueden aprender sin intervención de los adultos (Belloni, 2009; Gomes, 2008).

El aprendizaje sin un enseñante en los ambientes virtuales (autodidaxia no ciberespacio) solo es una de las formas que vienen de las TIC y constituye un proceso que debe ser complementario a las prácticas de enseñanza más tradicionales. Sin dispensar otras modalidades, este aprendizaje actúa como potenciador del desarrollo de las competencias necesarias para el proceso de cognición, en la medida en que estimula la autonomía, la colaboración, la organización y la realización de múltiples tareas. En el aprendizaje ubicuo, la autodidaxia es el elemento central, pues da las bases para la constitución de las competencias asociadas a este nuevo modo de aprendizaje.

El e-learning o aprendizaje electrónico, por otra parte, es un modelo que sustituye la antigua educación a distancia. En la era de la hipermovilidad y todas sus transformaciones, las prácticas ubicuas cambiaron en los individuos las nociones de presencia, ausencia y distancia. Las herramientas de educación online se han sofisticado en la medida en que nuevas tecnologías emergen, y a través de plataformas de contenidos estáticos, los nuevos ambientes de e-learning permiten la realización de conferencias, hospedaje de contenido audiovisual e interactivo, y también el uso de herramientas de administración del tiempo y planeamiento de estudios.

La convergencia mediática y el surgimiento de los ordenadores móviles crearon nuevas posibilidades de e-learning, resultando un nuevo paradigma de aprendizaje virtual: el m-learning o aprendizaje móvil. Este añade la movilidad a las prácticas de educación online: el estudiante es quien decide, más allá de la hora y el tiempo de estudios, la ubicación dónde va a acceder el contenido. A pesar de utilizarse en las nuevas herramientas computacionales, estos paradigmas pertenecen al campo de la educación formal, en la medida en que tienen por objetivo principal un proceso de aprendizaje de sistema pre-definido.

La revolución tecnológica y la popularización de los dispositivos móviles digitales promovieron un cambio en el comportamiento de consumo informacional. Los aparatos multimedia y multitareas invadieron el cotidiano de los usuarios y los nuevos hábitos de interacción pasaron a reflejarse en la dinámica de las prácticas sociales. La comunicación híbrida, instantánea, descentralizada y fragmentaria - característica del ciberespacio - con la hipermovilidad pasó a invadir las ciudades, inaugurando nuevas formas de re- 
lación y dinámicas sociales. En este contexto, la deficiencia de la enseñanza tradicional se ve acentuada y enfatiza la necesidad de una reformulación de las prácticas educativas.

En el ámbito de los medios de comunicación, hace algunos años los investigadores sostienen que las TIC deben incorporarse a la enseñanza, en la medida en que presentan funcionalidades que pueden potenciar los procesos de aprendizaje, así como están más alineadas al nuevo perfil cognitivo, principalmente de los niños y jóvenes. María Luiza Belloni, una de las precursoras en el estudio de la integración de las TIC al ambiente escolar, argumenta que ese movimiento es necesario para una mejora en la calidad y sobre todo para una democratización de la enseñanza. La autora defiende que la agregación de estas tecnologías puede promover una educación para la ciudadanía:

La escuela debe integrar las tecnologías de información y comunicación porque ellas ya están presentes e influyentes en todas las esferas de la vida social, cabiendo a la escuela, especialmente a la escuela pública, actuar para compensar las terribles desigualdades sociales y regionales que el acceso desigual a estas máquinas están generando (Belloni, 2009, p. 10).

En la práctica, las cuestiones estructurales completan el proceso de integración de las TIC. Las dificultades económicas, la falta de políticas públicas que capaciten a los educadores, así como la necesidad de reformulación de las metodologías y dinámicas de enseñanza, parecen hacer un poco utópicas previsiones abreviadas de un cambio completo en ese sistema. Aún más si se considera el sistema público de educación donde la incipiente inclusión digital retrasa las fases importantes requeridas por la dinámica de la cultura digital. Porque la cultura de la convergencia es una vía de mano doble, requiere el sujeto conectado tecnológica y mentalmente.

El dominio de las competencias mediáticas, en lo que se refiere al lenguaje, permite al ciudadano analizar de forma crítica los mensajes que recibe y también realizar su comunicación de forma efectiva. En el ambiente hiperconectado y fluido, el lenguaje es la instancia que propicia la correlación con los modos de producción de lo que se ve en la interfaz del producto, como por ejemplo: una red social, un sitio, una aplicación. También es a través del lenguaje que la competencia estética del individuo y la sensibilidad para reconocer la calidad estética de una producción son accionadas. Así, el lenguaje potencia el proceso de cognición, en la medida en que estimula la conexión con las demás competencias. 
En contra de las dificultades de la enseñanza colectiva, las modalidades de aprendizaje más personalizadas e individualizadas crecen a medida que aplicaciones y plataformas de enseñanza digital se popularizan en los ambientes virtuales. Los modelos e-learning, m-learning, la autodidaxia y el aprendizaje ubicuo se derivan de las nuevas prácticas en la hipermobilidad y plantean nuevos desafíos a los productores de contenido y a los educadores. A continuación, presentaremos más detalladamente estas tipologías.

El aprendizaje ubicuo deriva de este nuevo ambiente hiperconectado y aunque incorpore características del m-learning - no es constituyente de un plan educativo, es totalmente informal, "espontaneo, contingente, caótico y fragmentario" (Santaella, 2013, p. 303). Desde el surgimiento de la radio y la televisión, con los reportajes y programas informacionales, los medios de comunicación se convirtieron en fuentes de educación informal. Con los ordenadores, ese tipo de educación pasó a ocupar el día a día de los usuarios, que pueden fácilmente acceder a noticias, literatura, tutoriales y vídeos. Con los dispositivos móviles, el acceso a los contenidos digitales ha quedado más disponible, cualquier persona que porte uno de esos aparatos puede acceder a acervos virtuales, hacer búsquedas y obtener todo o tipo de información. Sin embargo, Santaella argumenta que ese modelo no sustituye a los otros tipos de aprendizaje y que debe actuar en conjunto con los modelos anteriores. Así como los medios que forman una red denominada de "ecología mediática" — en que nuevos medios y los tradicionales se integran-, este potencial híbrido de las ecologías se muestra también en las nuevas prácticas de educación que derivan de los medios.

\section{Geekie Games: las nuevas modalidades de aprendizaje}

Con la popularización de los dispositivos móviles, principalmente los Smartphone, ha empezado uno de los más promisores segmentos de la industria tecnológica: el desarrollo de aplicaciones. ${ }^{1}$ Sin embargo, pocas iniciativas, sobre todo gratuitas, exploran las potencialidades de estos programas en prácticas de enseñanza. Muchos juegos, quizzes y pasatiempos usan, informal y espontáneamente, procesos de aprendizaje, es decir, estimulando

1 A pesar de la situación económica, Brasil ha generado, en 2015, aproximadamente 25 mil millones de dólares en el sector. El Ministerio de Ciencia, Tecnología e Innovación prevé superar en 2017 la marca de 70 mil millones. Con todo el potencial de consumo, centenares de apps están disponibles diariamente en las plataformas de distribución para los más distintos fines. 
prácticas del aprendizaje ubicuo, pero la mayoría aún está relacionada con las producciones de entretenimiento.

En Brasil podemos destacar Geekie Games, una aplicación desarrollada por la Fundación Lemann en asociación con otras instituciones del sector privado y con el apoyo del Ministerio de Educación. La aplicación tiene como objetivo auxiliar a los candidatos en los estudios para el ENEM (Exame Nacional do Ensino Médio) y está disponible en tiendas online de dispositivos móviles con el sistema Android. El usuario puede acceder a los simuladores, vídeo-clases expositivas animadas, tutoriales, imágenes y ejercicios específicos de cada disciplina. Al descargar el software, el usuario realiza su catastro y selecciona el curso que pretender seguir (Figura 1a). En nuestro acceso contamos 607 opciones, entre cursos técnicos, bachilleratos y licenciaturas. Después de elegir el curso y el tiempo semanal de dedicación, un plan de estudios es elaborado de acuerdo con las necesidades del candidato (Figura 1b y 1c). Para cada temática propuesta hay un análisis del repertorio sobre el tema, el Rayo X Inicial, la clase y el Check Final (un ejercicio para evaluar y revisar el contenido).

\section{Figura 1}

\section{Interfaces iniciales de Geekie Games}

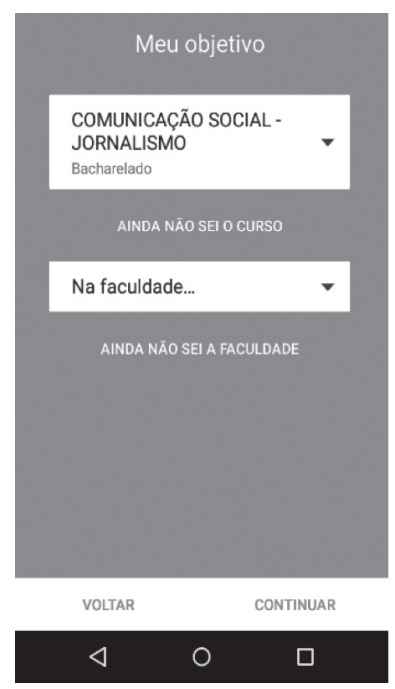

(a)

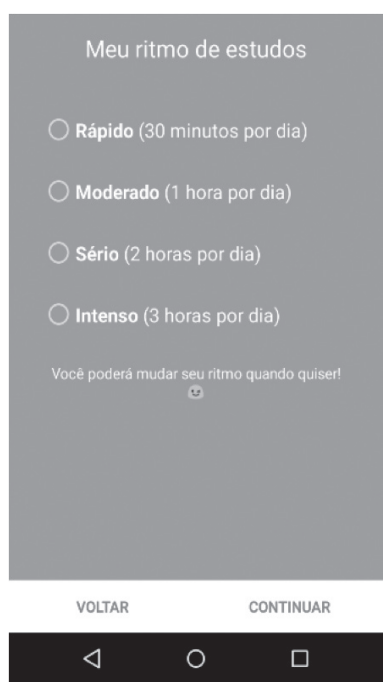

(b)

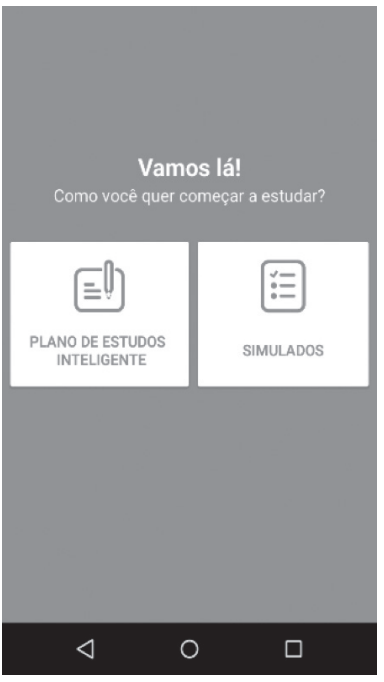

(c)

Fuente: las autoras 
Es posible notar el carácter individualizador de la herramienta, pues se ofrece al usuario la posibilidad de seleccionar un contenido más personalizado, alineado a sus demandas. Cada clase tiene aproximadamente 20 diapositivas. Ellas son divididas en las cuatro grandes áreas del conocimiento exigidas en el ENEM: matemáticas y sus tecnologías; ciencias humanas y sus tecnologías; lenguajes y códigos; ciencias de la naturaleza y sus tecnologías. Normalmente, las video-clases tienen el audio del profesor seguido de la ilustración de una pizarra que se va cambiando mientras ocurre la explicación. También se muestran textos e imágenes digitalizados. En los ejercicios integrados a las clases, al seleccionar la respuesta, correcta o no, el programa marca y justifica la respuesta adecuada.

Se nota que distintos sentidos son estimulados mientras se da la navegación: más allá de la vista, tradicionalmente utilizada en lecturas, los aprendientes movilizan oído y tacto. Los diferentes elementos que componen la interfaz de la aplicación activan en un alto nivel la percepción de los usuarios.

Con la "tactibilidad" - función característica de los dispositivos con pantallas táctiles - la relación física entre tecnología e individuo es estrechada. De la misma forma, la ruta de navegación o el modo de fruición del mensaje son individualizados. En la interacción, la sensorialidad del tacto y la experiencia del manejo material traen una nueva forma de procesamiento cognitivo que extrapola las operaciones mentales. El usuario, por ejemplo, a fin de identificar algún elemento de una imagen puede aumentarla o disminuirla, pausar el vídeo, arrastrar y pasar la diapositiva y, respecto a los ejercicios, puede efectivamente modificar aquel contenido.

Dialogando con las ideas de McLuhan - que comprendía los medios como extensiones del hombre y fue uno de los precursores del estudio de la tactibilidad-, Palacios y Cunha (2012) argumentan que la tactibilidad genera un alto involucramiento sensorial, contrariando la anestesia de sentidos promovida por siglos de vivir en la "Galaxia de Gutenberg" (McLuhan, 1972).

El retorno del involucramiento físico con los medios, propiciado por las nuevas tecnologías en las interfaces hápticas, tiene su auge en las transformaciones cognitivas, así como en la cognición distribuida ${ }^{2}$ (proceso que tiene en cuenta la relación con el ambiente, las interacciones sociales y con

2 Teoría desarrollada por Edwin Hutchins, que entiende la cognición como un fenómeno contextualizado, que tiene en cuenta el ambiente, enfatizando el carácter social y cultural del procesamiento de los mensajes. 
los sistemas computacionales). Los estímulos neurales se materializan en el toque. En la navegación en las pantallas táctiles, muchas decisiones son tomadas intuitiva e instantáneamente al toque de nuestros dedos. Esa funcionalidad, así como muchas otras al largo de la evolución humana, ha sido naturalizada por nuestros cuerpos y mentes con una eficacia comunicativa.

Más que sustituir la función del cursor y del ratón, la tactibilidad simula la manera cómo manejamos objetos físicos en nuestro día a día. Es establecida una relación de más intimidad e involucramiento con el contenido, aproximando al usuario, que cambia su manera de interacción. Delante de la dificultad de comprender una información específica, por ejemplo, el individuo, través del toque, busca conocer más sobre el contenido y, por tanto, su envolvimiento táctil se vuelve más amplio, sea manipulando imagen, texto, vídeo etc.

Esos múltiples estímulos demandan nuevas competencias de los usuarios. Ellos necesitan organizar las informaciones que reciben y distribuir la atención para las diversas tareas que realizan al mismo tiempo. Esas competencias son estimuladas, principalmente, fuera de los ambientes de aprendizaje. Al gestionar un perfil en Facebook, crear un foro, enviar un correo electrónico, acceder a documentos online, enviar informaciones de tráfico a Waze, etc., los usuarios adquieren más habilidades operacionales y mentales que los hacen cada vez más hábiles para interactuar con los nuevos medios y, concomitantemente, de forma espontánea aumentan sus repertorios culturales.

Para Ferrés (2012), la competencia que el individuo posee para comprender los mensajes en su complejidad de códigos y las multimodalidades del ambiente digital, están involucradas en algunas dimensiones como la tecnológica, la del lenguaje, de la ideología y los valores, los procesos de interacción, de producción y difusión, y también en la dimensión estética. Sin duda la competencia tecnológica (Ferrés 2012), es decir, la comprensión del funcionamiento de las herramientas de comunicación a fin de entender cómo los mensajes son elaborados y la capacidad de usarlos, se potencia cuando la tactilidad tiene la función de pasar de un flujo a otro de informaciones través la pantalla.

Como ya dijimos, el dominio de las competencias mediáticas en la dimensión del lenguaje, permite analizar de forma crítica los mensajes y comunicarlos efectivamente a través de los distintos tipos de tecnología disponibles, ya que es el lenguaje el que proporciona la correlación entre todos los elementos que se ven en la interfaz de un producto (una red social, un sitio web, una aplicación como Geekie Games, etc.). 
Creemos que es también en la dimensión del lenguaje donde la competencia del individuo para la dimensión estética se expresa, ya que se entiende que la habilidad accionada tiene que ver con la sensibilidad que, desde nuestro punto de vista, reconoce la calidad en las formas, los colores, en la distribución espacial de los elementos, en la composición de la escena y dependiendo del lenguaje de producción - también en la unión de las escenas para la creación de un producto. Así, es posible decir que el lenguaje potencia el proceso de cognición sensible y también emocional, reconfigurado ahora por la tactibilidad, en la medida en que estimula la conexión con las demás competencias. El lenguaje estimula la sensibilidad que guía el proceso de producción de sentido y la competencia de los procesos de interacción con una postura activa delante de las pantallas, para interactuar con los contenidos y evaluar críticamente los elementos emocionales, racionales y contextuales de un mensaje.

Creemos también que cuanto más grande es la habilidad del individuo (competencia) en el universo digital, más grande es la comprensión de las ideologías, valores y polifonías que el nuevo ecosistema social propicia (nos referimos al ambiente hiperconectado donde los procesos de producción y difusión son los grandes gestores que articulan el conocimiento y permiten la cognición diferenciada). Entender las diferentes funciones de los procesos de producción y difusión por las cuales pasa un producto de comunicación, significa estar atento a las posibilidades de ser un "prosumidor".

La convergencia reconfigura los procesos de distribución y difusión de la cultura y del conocimiento. Eso pasa en la propia vida cotidiana, en el presente de los acontecimientos, en el momento en que podemos acceder - en cualquier sitio y tiempo - a bancos de datos, archivos en nubes, múltiples pantallas que traen informaciones, interacciones y conexiones para el conocimiento con varias finalidades. Aunque de manera tímida, no hay cómo negar que sea la competencia tecnológica la fuente motriz de los cambios.

En el caso de Geekie Games, el estímulo es para un consumo colectivo y participativo que ocurre en las herramientas de interacción con el usuario. Ya en el primer acceso son sincronizados los contactos de Facebook del usuario, se muestran los amigos que usan la aplicación y se ofrece la posibilidad de invitar nuevos amigos (Figura $2 \mathrm{a}$ y b). 
Figura 2

El consumo colectivo de Geekie Games

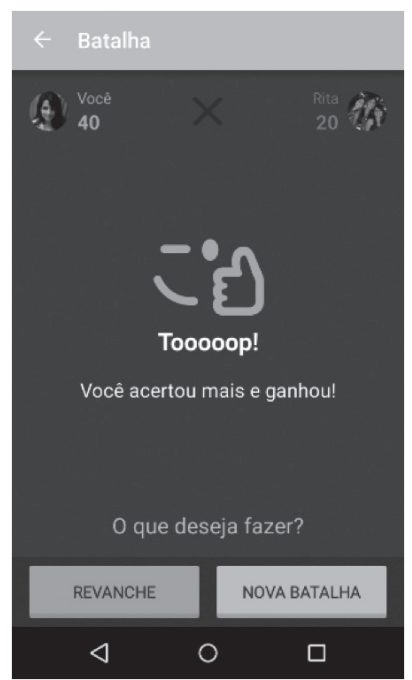

(a)

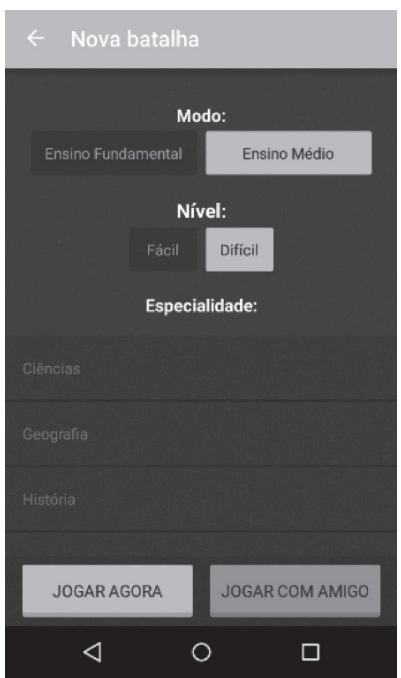

(b)

Fuente: lwas autoras

\section{Conclusiones}

Vimos que la aprehensión de contenidos compuestos por signos de distintas naturalezas exige habilidades de utilizar múltiples estímulos sensoriales, potenciando la comprensión del mensaje y accionando competencias para fluir en diferentes dimensiones con el lenguaje y los estímulos recibidos. Si hay falta de dominio de un código, por ejemplo, el usuario puede utilizar otros recursos.

En las actuales sociedades hipercomplejas, hibridadas y ubicuas, de cultura participativa y colaborativa, la comunicación mediada por dispositivos móviles es más adecuada a la realidad y al nuevo perfil de consumo de mensajes. El gran cambio proporcionado por la comunicación ubicua es la relación de los ambientes virtuales con los físicos, con el propio cuerpo y el potencial personalizante, lúdico y espontáneo de las prácticas ubicuas. La aplicación Geekie Games, por ejemplo, utiliza recursos propios de los jue- 
gos y redes sociales para que el contenido sea atractivo y para identificar el consumo del contenido educacional y de los medios de entretenimiento.

Creemos que el carácter más espontáneo, emergente de las nuevas modalidades de enseñanza-aprendizaje, no debe ser despreciado. Es más, los nuevos estudios que se propongan evaluar la capacidad comunicacional de los usuarios deben tener en cuenta el impacto de los estímulos multisensoriales con los que interactúan esos individuos, ya que gran parte de las decisiones y del procesamiento cognitivo derivan, hoy, de estímulos menos racionales que intuitivos.

Todos estos cambios, la nueva ecología mediática, el cambio del perfil cognitivo de los usuarios y las nuevas teorías que surgen en ese panorama, implican una reformulación del sistema educacional: una enseñanza más descentralizada y horizontal, que amenaza el sistema cartesiano tradicional. Se necesitan nuevas políticas públicas que capaciten a los educadores, garanticen estructura para que los ambientes escolares puedan volverse ubicuos y que se desarrollen estrategias para que, en esas ecologías, cohabiten las potencialidades de cada medio y sean creadas metodologías que incluyan ese panorama cada vez más híbrido.

En la era de la conectividad y en un ambiente conectivo tenemos un sujeto que experimenta el lenguaje y que desempeña muchas tareas, donde las TIC pasan a ser también TAC (tecnologías de aprendizaje y conocimiento) que hacen surgir un nuevo ambiente prácticas comunicativas distintas de acuerdo con los objetivos deseados. Las tecnologías de aprendizaje y conocimiento, al configurar un nuevo ambiente educativo, moldean también de manera profunda las experiencias culturales de las personas que participan de manera activa de las plataformas de los medios educativos y sociales. Entonces, de ese ambiente hiperconectado deben emerger sujetos críticos con prácticas educomunicativas diferentes a las de sus padres.

Ciertamente, existen tensiones entre los diferentes tipos de aprendizajes formales e informales dentro y fuera de las escuelas, porque el aprendizaje ubicuo transforma también la noción de tiempo y espacio, y porque las plataformas digitales unidas con los dispositivos móviles proyectan la educación a otro nivel cualitativo, a través de la comunicación integrativa, participativa y colaborativa. La conectividad es un entorno en desarrollo, con nuevas estructuras de enseñanza, con derecho a interlocución a través de la tecnología y con diversidad de prácticas educativas, donde los medios de 
comunicación están en el orden del día así como las competencias para disfrutar de sus beneficios.

\section{Bibliografía}

Araujo, R. (2003). Computação Ubíqua, Princípios, Tecnologias e Desafios. Simpósio Brasileiro de Redes de Computadores, 21, 45-115.

Belloni, M. (2009). O que é mídia-educação. São Paulo: Campinas.

Gomes, N. (octubre, 2008). Infância, mídias e aprendizagem: autodidaxia e colaboração. Educação \& Sociedade Educação \& Sociedade, 29(104), 717746. Campinas, Brasil: Centro de Estudos Educação e Sociedade.

Bottentuit Junior, J. (2012). Do Computador ao Tablet: Vantagens Pedagógicas na Utilização de Dispositivos Móveis na Educação. LATEC/UFRJ, 6(1), 125-149. Laboratório de Pesquisa em Tecnologias da informação e da Comunicação da Universidade Federal do Rio de Janeiro. Disponible en https://bit.ly/2wmQc9n/

Fantin, M. (2012). Cultura Digital e Escola: pesquisa e formação de professores. São Paulo: Papirus.

Ferrés y Prats, J. (2014). Las pantallas y el cerebro emocional. Barcelona: Romanya Valls.

Piscitelli, A. (2012). La competencia mediática: propuesta articulada de dimensiones e indicadores. Comunicar, revista iberoamericana de comunicación y educación, 19(38), 75-82. Andalucía, España. Disponible en https://bit. 1y/2P3WQJI/

Fígaro, R. (2010). Estudos de recepção para entender os usos da mídia na escola. Comunicação \& Educação, 15(3), 17-28. Disponible en https://bit. $1 \mathrm{y} / 2 \mathrm{w} 4 \mathrm{D} 35 \mathrm{~J} /$

Jenkins, H. (2009). Cultura da Convergência. São Paulo: Aleph.

Lemos, A. (julio-diciembre, 2013). Cultura da Mobilidade. Revsita Famecos, 12(2). Porto Alegra, Brasil.

Lévy, P. (2007). Cibercultura. São Paulo: Editora 34.

Lévy, P. (1999). A inteligência coletiva: por uma antropologia do ciberespaço. São Paulo: Loyola.

Magnoni, A., Affini, L. y Américo, D. (2007). Da Mobilidade a Ubiqüidade da Comunicação. II Colóquios Multitemáticos em Comunicação. Santos: Intecom. Disponible en https://bit.ly/2MKJ3tW/ 
Mcluhan, M. (1964). Os meios de comunicação como extensões do homem. São Paulo: Cultrix.

Mcluhan, M. (1972). A galáxia de Gutenberg: a formação do homem tipográfico. São Paulo: Edusp.

Ortiz, A., Affonso, L. y Timponi, R. (eds.) (2012). Tecnologias de comunicação e cognição. Porto Alegre: Salinas.

Santaella, L. (2010). A ecologia pluralista da comunicação. São Paulo: Paulus.

Santaella, L. (2013). Comunicação ubíqua. Repercussões na cultura e na educação. São Paulo: Paulus.

Santaella, L. (2005). Semiótica Aplicada. São Paulo: Pioneira Thomson Learning.

Santaella, L. (2008). Mídias locativas: a internet móvel de lugares e coisas. Revista Famecos, 1(35). Recuperado de https://bit.ly/2o943wu/

Palacios, M. S. y Cunha, R. (2012). A tactilidade em dispositivos móveis: primeiras reflexões e ensaio de tipologias. Contemporânea, revista de comunicação e cultura, 10(3), 658- 685. Universidad Federal de Bahía. Recuperado de https://bit.ly/2BIJj8v/

Fecha de recepción: 2018/03/22; Fecha de aceptación: 2018/08/19;

Fecha de publicación: 2018/09/01 